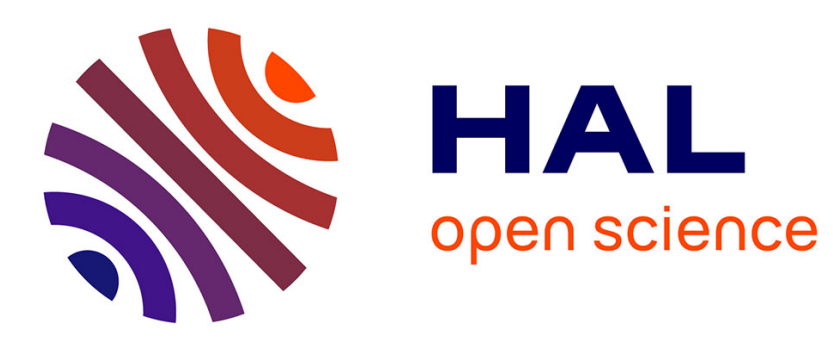

\title{
Diethyl ether pyrolysis study in a jet-stirred reactor
} Nicolas Vin, Olivier Herbinet, Frédérique Battin

\section{To cite this version:}

Nicolas Vin, Olivier Herbinet, Frédérique Battin. Diethyl ether pyrolysis study in a jet-stirred reactor. Journal of Analytical and Applied Pyrolysis, 2016, 121, pp.173 - 176. 10.1016/j.jaap.2016.07.018 . hal-01433850

\section{HAL Id: hal-01433850 https://hal.science/hal-01433850}

Submitted on 13 Jan 2017

HAL is a multi-disciplinary open access archive for the deposit and dissemination of scientific research documents, whether they are published or not. The documents may come from teaching and research institutions in France or abroad, or from public or private research centers.
L'archive ouverte pluridisciplinaire $\mathbf{H A L}$, est destinée au dépôt et à la diffusion de documents scientifiques de niveau recherche, publiés ou non, émanant des établissements d'enseignement et de recherche français ou étrangers, des laboratoires publics ou privés. 


\title{
Diethyl ether pyrolysis study in a jet-stirred reactor
}

\author{
Nicolas Vin, Olivier Herbinet, Frédérique Battin-Leclerc* \\ Laboratoire Réactions et Génie des Procédés (LRGP), CNRS, Université de Lorraine, ENSIC, 1 \\ rue Grandville, BP 20451, 54001 Nancy Cedex, France \\ doi:10.1016/j.jaap.2016.07.018 \\ Published in Journal of Analytical and Applied Pyrolysis 121 (2016) 173-176
}

\begin{abstract}
This paper reports new experimental measurements for the pyrolysis of diethyl ether at temperatures between 600 and $1100 \mathrm{~K}$ under dilute conditions. This work was performed using a jet-stirred reactor at pressures from $26.7 \mathrm{kPa}$ (200 Torr) to $107.7 \mathrm{kPa}$ (800 Torr) with dilution in helium, for residence time from 1 to $10 \mathrm{~s}$ and an inlet fuel concentration from 1 to $5 \%$. Temperature was the parameter with the largest influence on reactivity. The complete destruction of diethyl ether was observed from $1080 \mathrm{~K}$. A decrease of residence time and pressure also slightly decreased reactivity, but the effect of pressure remained very limited. Major products were carbon monoxide, methane, ethylene and acetaldehyde. Minor products were ethane, acetylene, propane, propene, ethanol, 1,3-butadiene, and benzene. Two literature models including diethyl ether reactions have been used to simulate these results, with in both cases a satisfactory agreement between experiments and simulations for fuel conversion and the formation of most of the products. Simulations using a literature model for the thermal decomposition of diethyl sulfide indicated that in the studied conditions, the sulfur compound would be completely decomposed at a temperature about $100 \mathrm{~K}$ lower than the oxygenated reactant.
\end{abstract}

Keywords: Diethyl ether; Pyrolysis; Jet-stirred reactor

\footnotetext{
* Corresponding author:

Frédérique Battin-Leclerc: E-mail: Frederique.Battin-Leclerc@univ-lorraine.fr,

Phone: +33 3831751 25, Fax: +33 383378120
} 


\section{Introduction}

The primary purpose of this study was to investigate the gas-phase pyrolysis of diethyl ether $\left(\mathrm{C}_{2} \mathrm{H}_{5} \mathrm{OC}_{2} \mathrm{H}_{5}\right)$ as a non-toxic model molecule for yperite $\left(\mathrm{ClC}_{2} \mathrm{H}_{5} \mathrm{SC}_{2} \mathrm{H}_{5} \mathrm{Cl}\right)$ in order to favor the development of a new process for the remediation of soils polluted by heavily toxic chemical. This new apparatus is based on the thermal desorption of the gaseous toxic compounds followed by their thermal decomposition in a dedicated high-temperature tubular reactor maintained at low pressure [1].

However a better knowledge about the gas phase reactions of diethyl ether (DEE) is also useful to favour the use of this molecule as biofuel. Like dimethyl ether, DEE has attractive properties for use in diesel engines, especially a high cetane number (above 125) [2], as well as a higher energy density than dimethyl ether and ethanol. DEE has also been proposed as a possible octane improver in biogas homogeneous charge compression ignition (HCCI) operation [3]. DEE can be produced from the catalytic dehydration of ethanol [2] and is easier to use in engine than dimethyl ether since it is liquid under ambient conditions.

Due to its promising properties as biofuel, the combustion kinetics of DEE has already been investigated using different experimental devices: burners with laminar premixed flames for flame speed measurements [4] or product analyses [5], a burner with non-premixed flames [6], shock tubes for ignition delay time determinations [7] and [8], a rapid compression machine for ignition delay time measurements [8]. On the other hand, there is only one experimental study about DEE pyrolysis performed in a shock tube [7].

The purpose of the present study is to investigate the pyrolysis of DEE in a jet-stirred reactor (JSR), a type of reactor which has been shown a suitable tool for kinetic studies involving product analyses [9].

\section{Experimental methods}

The experimental study has been performed using a spherical fused silica JSR (volume of $85 \mathrm{~cm}^{3}$ ) inside which the reactants enter through an injection cross made of four nozzles which is located at its center. High turbulence is created by gas jets through the nozzles and leads to homogeneity in composition and temperature of the gas phase. The isothermal JSR is preceded by a quartz annular preheating zone in which the temperature of the gas is increased up to the reactor temperature. The gas mixture residence time inside the annular preheater is very short compared to its residence time inside the reactor (a few percent). Both the reactor and the preheating zone are heated by the means of Thermocoax resistances rolled up around the reactor. The reaction temperature is measured by a thermocouple located inside the intra-annular space of the preheating zone; its extremity being placed at the level of the injection jets.

DEE is provided by Sigma-Aldrich (purity of $\geq 99.5 \%$ ) and used diluted in helium provided by Messer with a purity reported as $99.999 \%$. The gas flow rate is controlled by a mass flow controller, the liquid flow rate by a Coriolis flow controller followed by a vaporization chamber maintained at $323 \mathrm{~K}$. The uncertainty in the flow measurements is around $0.5 \%$ for each controller, so about $1 \%$ on the residence time. 
The outlet gas leaving the reactor is analyzed by two gas chromatographs via a heated transfer line maintained at $433 \mathrm{~K}$ to avoid product condensation during transfer. The first chromatograph, equipped with a Carbosphere packed column, a thermal conductivity detector (TCD) and a flame ionization detector (FID), is used for the quantification of CO, methane, ethylene, acetylene and ethane. The second chromatograph is fitted with a PlotQ capillary column and a FID is used for the quantification of other types of molecules. The FID was preceded by a methanizer (nickel catalyst for hydrogenation) which made it possible to detect species like $\mathrm{CO}$ and $\mathrm{CH}_{2} \mathrm{O}$ with a good sensitivity. The identification of reaction products is performed using a gas chromatograph equipped with a PlotQ capillary column and coupled to a mass spectrometer (quadrupole). Calibrations are performed by injecting standards. The maximum relative error in mole fractions is estimated to be $\pm 5 \%$.

\section{Results and discussion}

DEE pyrolysis has been studied at temperatures from 600 to $1100 \mathrm{~K}$, pressures of 800 and 200 Torr, residence times from 1 to $10 \mathrm{~s}$, reactant inlet mole fractions of $1 \%, 2 \%$, and $5 \%$ with a dilution in helium. All the results are given in a spreadsheet in Supplementary material. Figure 1 presents the temperature evolution of the DEE conversion which has been obtained for all the studied conditions. This figure shows that DEE starts to be consumed at $825 \mathrm{~K}$ and is fully destroy for a temperature of $1080 \mathrm{~K}$. Figure 1 also indicates that apart from temperature, the only parameter presenting some significant impact on the DEE reactivity is residence time. This is confirmed by Figure 2 which displays the evolution of the DEE conversion with residence time and which shows a rise from 16 to $63 \%$ when the residence time is increased from 1 to $10 \mathrm{~s}$. At $925 \mathrm{~K}$, a decrease of the pressure from 800 to 200 Torr, for 5\% DEE inlet mole fraction and a residence time of $4 \mathrm{~s}$, leads to a decrease of the DEE conversion from 45 to $40 \%$. At the same temperature, a decrease of the DEE inlet mole fraction from 5 to $1 \%$, at 800 Torr and a residence time of 2 s, leads to a decrease of the DEE conversion from 30 to $28 \%$. A steady reactivity increase is observed for DEE inlet mole fraction from 1 to $5 \%$.

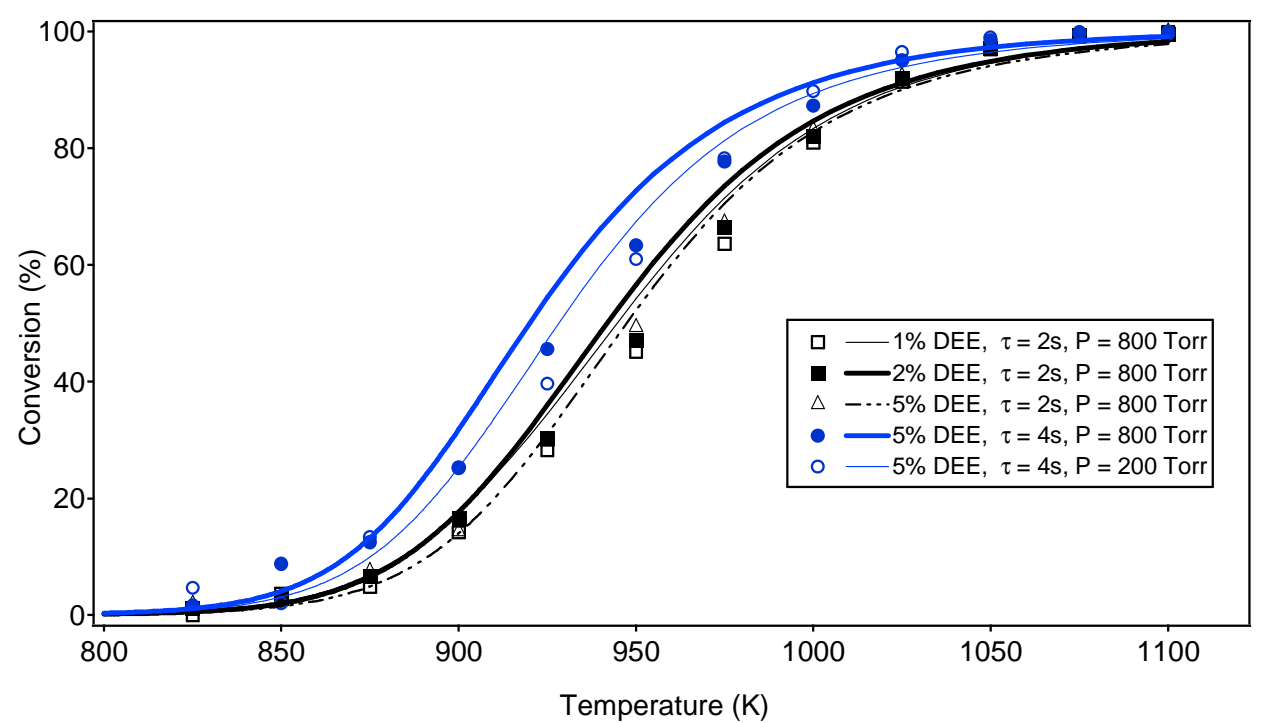

Figure 1: Temperature evolutions of the DEE conversion for various inlet mole fractions, residence time $(\tau)$ and pressure $(P)$. Symbols are experiments and lines simulations with the model of Tran et al. [5]. 


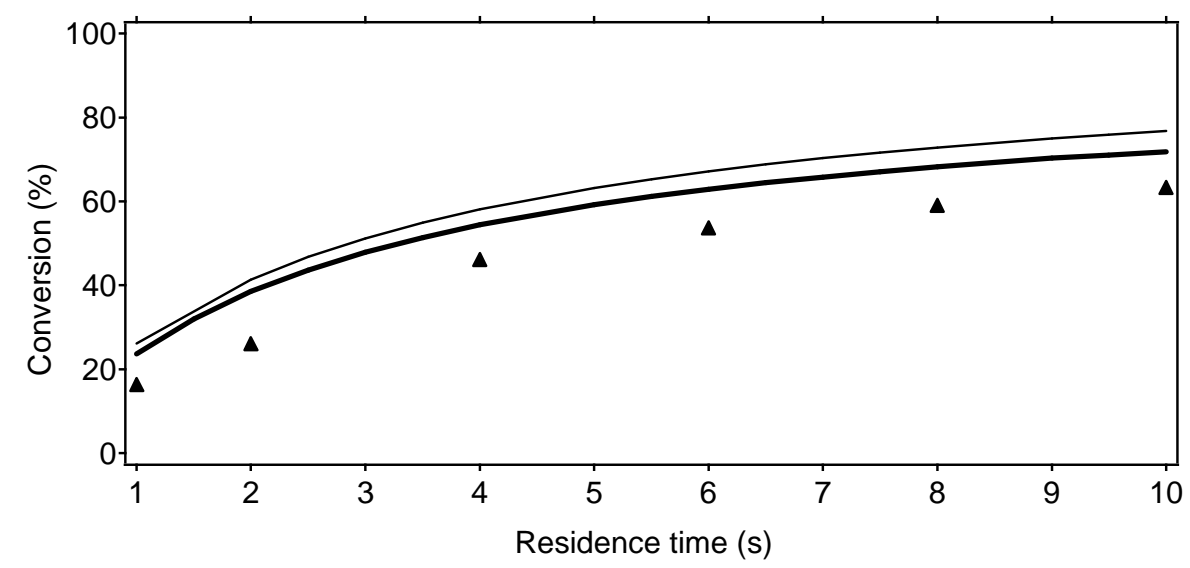

Figure 2: Evolutions of DEE conversion with residence time $(T=925 \mathrm{~K}, 5 \%$ DEE inlet mole fraction, $P=800$ Torr). Symbols are experiments, thick lines simulations with the model of Tran et al. [5], and thin lines simulations with the model of Yasunaga et al. [7].

Figure 3 displays the temperature evolution of the mole fractions of the products obtained during DEE pyrolysis. Two types of products can be distinguished: those presenting a maximum around $1000 \mathrm{~K}$ (ethylene, propane, propene, acetaldehyde, ethanol), and those the mole fraction of which continually increases (carbon monoxide, methane, 1,3-butadiene, benzene).
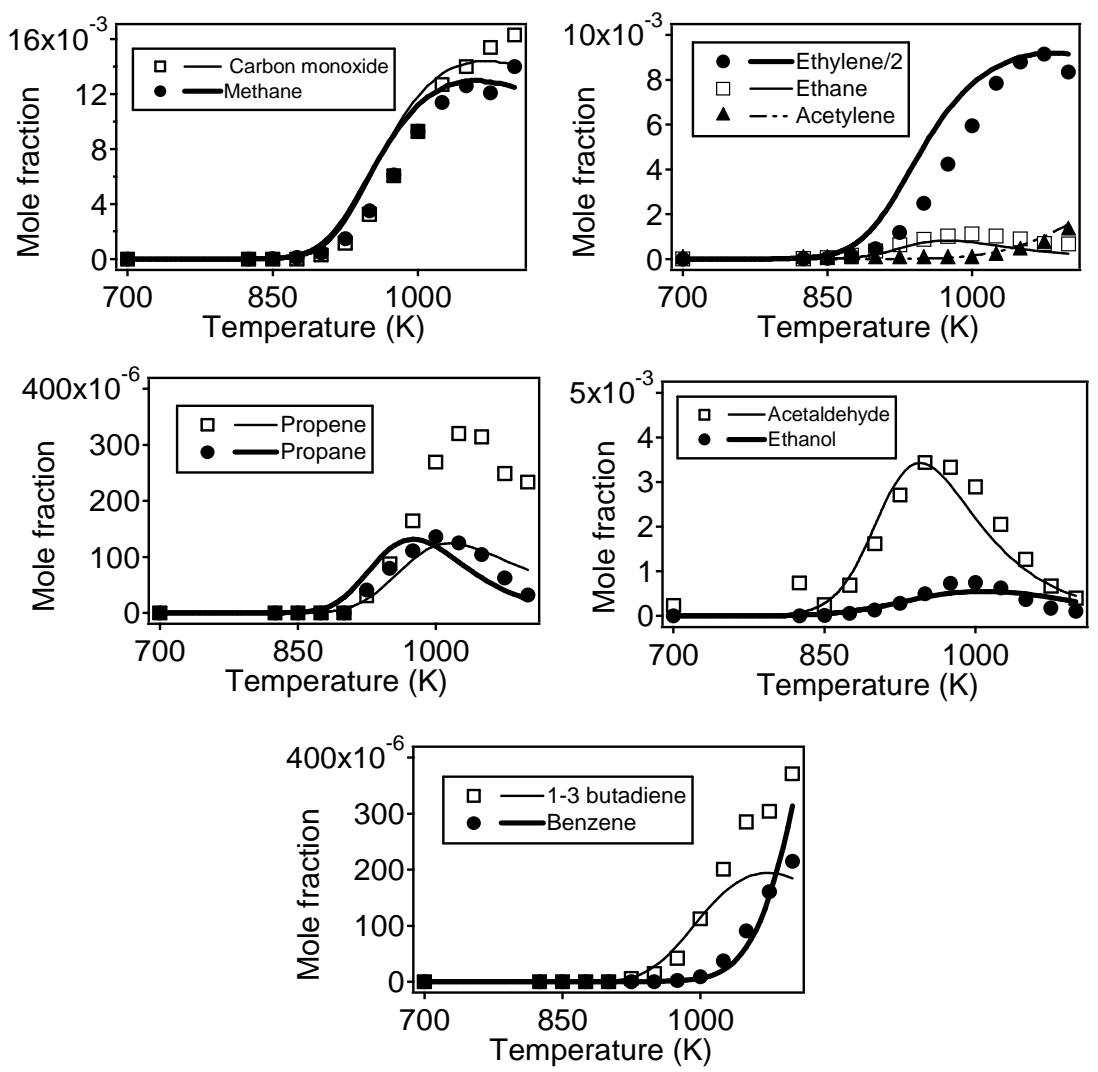

Figure 3: Temperature evolutions of mole fraction of the products obtained during DEE pyrolysis (2\% DEE inlet mole fraction, $\tau=2 \mathrm{~s}, P=800$ Torr). Symbols are experiments and lines simulations with the model of Tran et al. [5]. Experimental and simulated mole fractions of ethylene have been divided by 2 . 
Note that while this product should have been detected with our analytical method if it was formed in amounts above $1 \mathrm{ppm}$, no trace of formaldehyde was detected. Hydrogen was not analyzed. Figure 4 presents the selectivity at $1000 \mathrm{~K}$ of these products showing that the major products are carbon monoxide, methane, ethylene and acetaldehyde. Under every studied condition, the carbon atom material balance is checked to about $10 \%$ of the global inlet in atoms of carbon.

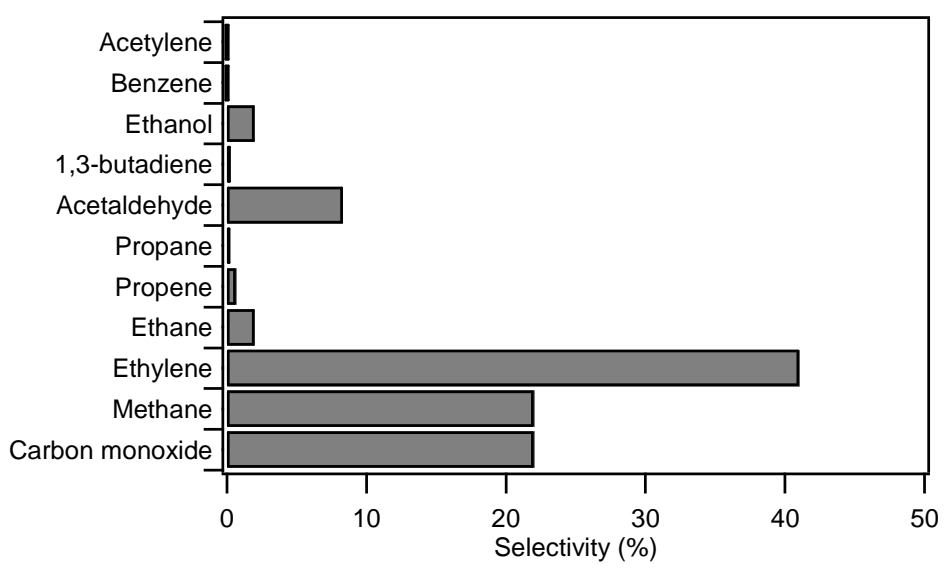

Figure 4: Selectivity of the products obtained of DEE pyrolysis (1000 K, 2\% DEE inlet mole fraction, $\tau=2 \mathrm{~s}, P=800$ Torr).

Simulations of experimental data were performed using the CHEMKIN package [10] and the OpenSMOKE + + framework [11]. Two literature detailed kinetic models were used:

The model of Yasunaga et al. [7] developed in 2010 to simulate data obtained in shock tubes for the pyrolysis and oxidation of DEE, and based on the $\mathrm{C}_{1}-\mathrm{C}_{4}$ hydrocarbon chemistry developed in Galway [12].

The brand new model of Tran et al. [5] developed to simulate species profiles obtained in a rich low-pressure laminar flame, and based on a tetrahydrofuran mechanism developed in Nancy [13] which includes a reaction base for $\mathrm{C}_{1}-\mathrm{C}_{4}$ unsaturated species, and benzene.

The simulations of our experimental results are shown in Figures 1 to 3 when using the model of Tran et al. [5] and 2, S1 and S2 (in Supplementary Material) when using model of Yasunaga et al. [7]. The agreement between our experiments and simulations using both models are satisfactory for the prediction of DEE conversion and most product formation. While, in the model of Yasunaga et al. [7], the rate constants of the reactions specific to DEE were mainly derived from estimations, in the model of Tran et al. [5], several of them were obtained using quantum chemistry computation method. However, the most recent model does not always lead to significant modeling improvements. Both models reproduce well the decrease of reactivity with pressure at a given temperature, with the model of Tran et al. [5] predicting better the extent of this decrease than the model of Yasunaga et al. [7]. The 2010 model simulates well the steady increase of reactivity when increasing DEE inlet mole fraction at a given temperature (see Figure S1), which is not the case of the model of Tran et al. [5] which, as shown in Figure 1, predicts a slight maximum of reactivity for an inlet DEE mole fraction of $2 \%$ which is not experimentally observed. Concerning product formation, the model of Tran et al. [5] reproduces well the formation of all 
the observed species, including 1,3-butadiene and benzene which were not considered in the model of Yasunaga et al. [7]. The only product for which significant deviation is observed between experiments and simulations with the model of Tran et al. [5] is propene. This species is well predicted by Yasunaga et al. [7]. However this last model overestimates notably the formation of acetylene, propane, and acetaldehyde, as shown in Figure S2.

Figure 5 displays the DEE consumption flow rate analysis at $1000 \mathrm{~K}$ obtained using the model of Tran et al. [5]:

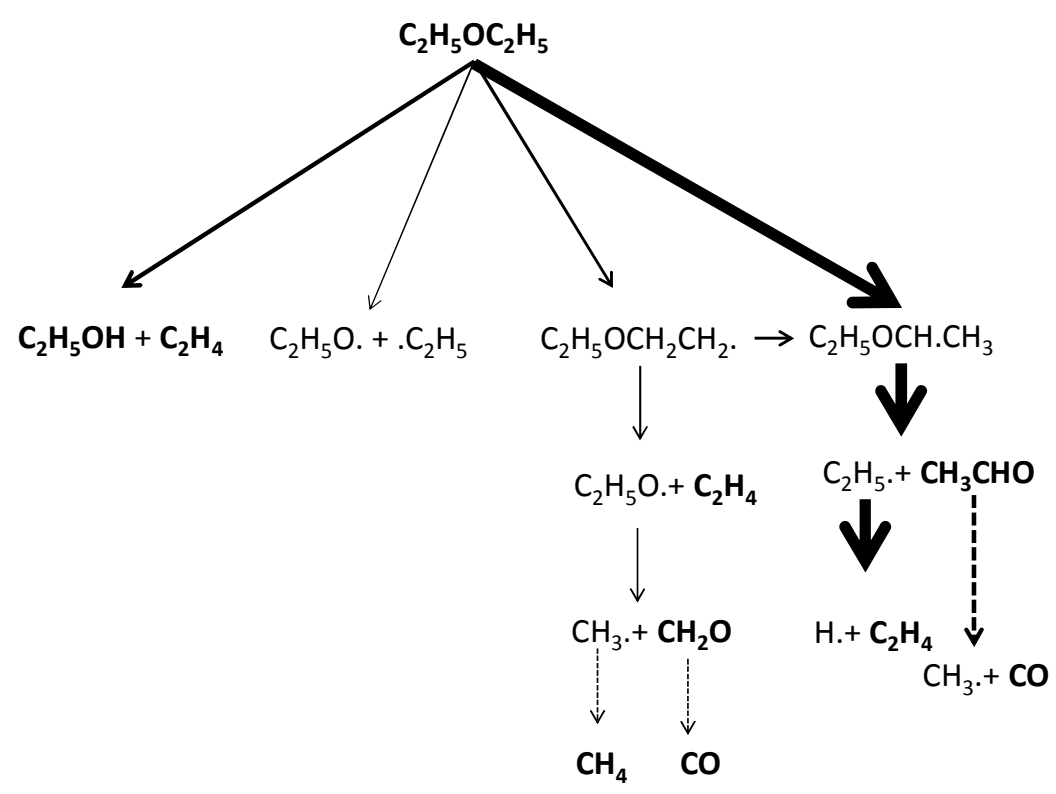

Figure 5: DEE consumption flow rate analysis according to the model of Tran et al. [5] (1000 K, $2 \%$ DEE inlet mole fraction, $\tau=2 \mathrm{~s}, P=800$ Torr). The size of the arrows is proportional to the flow rate of the related reaction. The broken lines correspond to reactions involving several elementary steps. Only major reactions are presented. Products in bold are those experimentally detected.

\subsection{DEE consumption}

Figure 5 shows that DEE is mainly consumed by $\mathrm{H}$-abstractions with methyl radicals and hydrogen radicals. $60 \%$ of DEE is there consumed to give $\mathrm{C}_{2} \mathrm{H}_{5} \mathrm{OCH} \bullet \mathrm{CH}_{3}$ radicals via secondary $\mathrm{H}$-atom abstractions and $15 \%$ to yield $\mathrm{C}_{2} \mathrm{H}_{5} \mathrm{OCH}_{2} \mathrm{CH}_{2} \bullet$ radicals via primary $\mathrm{H}$-atom abstractions. $19 \%$ of DEE is also consumed through the molecular reaction producing ethanol and ethylene, and $8 \%$ by unimolecular initiation giving ethyloxy and ethyl radicals.

\subsection{Product formation}

Figure 5 also indicates that $\mathrm{C}_{2} \mathrm{H}_{5} \mathrm{OCH} \bullet \mathrm{CH}_{3}$ radical readily decomposes by $\beta$-scission to give acetaldehyde and ethyl radicals. While $15 \%$ of $\mathrm{C}_{2} \mathrm{H}_{5} \mathrm{OCH}_{2} \mathrm{CH}_{2} \bullet$ radical isomerizes yielding $\mathrm{C}_{2} \mathrm{H}_{5} \mathrm{OCH} \bullet \mathrm{CH}_{3}$ radical, the major consumption pathway of this radical is also $\beta$-scission, producing ethylene and ethyloxy radicals. Ethyl radicals react mainly to give ethylene, but they are also the source of propane via recombination with methyl radicals, and of ethane via $\mathrm{H}$-abstractions. Ethylene leads to acetylene via the formation of vinyl radicals, to propene via the addition of 
methyl radicals followed by H-elimination, and to 1,3-butadiene through the addition of vinyl radicals followed by H-elimination. Ethyloxy radicals decompose mainly to give formaldehyde and methyl radicals. At $1000 \mathrm{~K}$, aldehydes are a significant source of carbon monoxide. Methyl radicals react mainly by $\mathrm{H}$-abstractions with DEE and hydrogen, but also with aldehydes, to yield methane. While its formation is better predicted by the model than that of propene, benzene is mainly produced from the combination of propargyl radicals, the formation of which derives from that of propene via reactions of allyl radicals and allene.

To better see the important reactions for DEE consumption, a sensitivity analysis is presented in Figure S3 of Supplementary Material. This figure shows that, apart $\mathrm{H}$-abstractions with $\mathrm{H}$-atoms and $\mathrm{CH}_{3} \bullet$ radicals from DEE and acetaldehyde, the most sensitive reactions are reactions with pressure dependence (e.g. DEE unimolecular initiation with C-O bond breaking). An improvement of the modeling of this dependence could help refining the agreement between simulations and experiments.

\subsection{Comparison between diethylether and diethylsulfide}

To give an idea of the difference of reactivity between DEE and a compound actually containing sulfur such as yperite, the toxic gas of interest for our process, we have compared the simulated temperature evolutions of the DEE computed with the model of Tran et al. [5] and with that of diethylsulfide computed with the model of Zheng et al. [14] for $2 \%$ fuel inlet mole fraction, a residence time of $2 \mathrm{~s}$ and at pressure of 800 Torr. The detailed kinetic model of Zheng et al. [14] has been validated by modeling experimental oxidation data obtained in an atmospheric flow reactor operating at temperatures from 903 to $1013 \mathrm{~K}$. The obtained results are plotted in Figure 6 and indicate that the sulfur compound starts to react and is fully decomposed at a temperature about $40 \mathrm{~K}$ lower than the oxygenated reactant. This lower reactivity temperature is in agreement with the bond dissociation energies of the C-O bond in DEE (84.8 kcal/mol [15]) and of the C-S (72.5 kcal/mol [16]) bond in diethylsulfide. Note that, according to [16], the dissociation energies of $\mathrm{C}-\mathrm{H}$ bonds adjacent to the heteroatom are close for oxygen $(93.0 \mathrm{kcal} / \mathrm{mol})$ and sulfur $(92.2$ $\mathrm{kcal} / \mathrm{mol}$ ) atoms. However there is more difference for the $\mathrm{C}-\mathrm{C}$ bond dissociation energies adjacent to the heteroatom: $86.8 \mathrm{kcal} / \mathrm{mol}$ for the ether and $82.0 \mathrm{kcal} / \mathrm{mol}$ for the sulfur compound, which also promotes the decomposition of diethylsulfide.

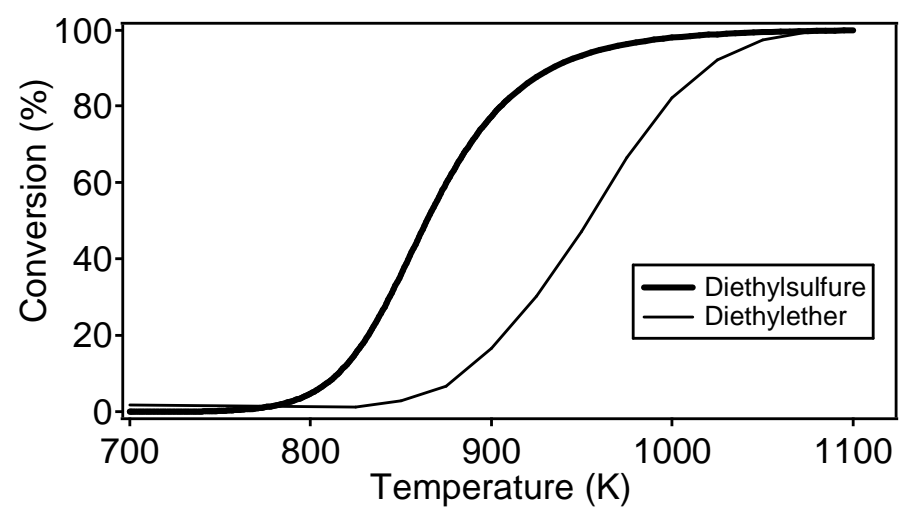

Figure 6: Comparison of the simulated temperature evolutions of the DEE computed with the model of Tran et al. [5] and diethylsulfide computed with the model of Zheng et al. [14] (2\% fuel inlet mole fraction, $\tau=2 \mathrm{~s}, P=800$ Torr). 


\section{Conclusion}

A first jet-stirred reactor study of the pyrolyis of DEE has been performed for temperatures from 600 to $1100 \mathrm{~K}$ and shows a complete destruction of this reactant around $1080 \mathrm{~K}$ for a residence time of $2 \mathrm{~s}$. While residence time has a significant effect on reactivity, pressure and DEE inlet mole fraction has a more limited one. Two recent literature models can well reproduce these effects, as well as the amount of product formation. Simulations also show that DEE display a reactivity similar to that of diethylsulfide at temperatures about $40 \mathrm{~K}$ lower for given residence time, pressure and reactant inlet mole fraction.

\section{Acknowledgements}

This work has been supported by TERbis, 943 rue Pasteur, 60700 Pont Sainte Maxence, France.

\section{Supplementary data}

Pdf file with supplementary figures

\section{References}

[1] R. Gourhan, Pour un procédé et dispositif pour traiter par pyrolyse des déchets fluides French patent 01 12783, 04/10/2001

[2] D.C. Rakopoulos, C.D. Rakopoulos, E.G. Giakoumis, A.M. Dimaratos, Characteristics of performance and emissions in high-speed direct injection diesel engine fueled with diethyl ether/diesel fuel blends, Energy, 43 (2012) 214-224

[3] K. Sudheesh, J.M. Mallikarjuna, Diethyl ether as an ignition improver for biogas homogeneous charge compression ignition (HCCI) operation - An experimental investigation, Energy, 35 (2010) 3614-3622

[4] F. Gillespie, W.K. Metcalfe, P. Dirrenberger, O. Herbinet, P.-A. Glaude, F. Battin-Leclerc, et al., Measurements of flat-flame velocities of diethyl ether in air, Energy, 43 (2012) 140-145

[5] L.S. Tran, J. Pieper, H.H. Carstensen, H. Zhao, I. Graf, Y. Ju, F. Qi, K. Kohse-Höinghaus, Experimental and kinetic modeling study of diethyl ether flames, Proc. Combust. Inst., 36 (2017) published on-line

[6] J. Hashimoto, K. Tanoue, N. Taide, Y. Nouno, Extinction limits and flame structures of 1-butanol and Diethyl Ether non-premixed flames, Proc. Combust. Inst., 35 (2015) 973-980

[7] K. Yasunaga, F. Gillespie, J.M. Simmie, H.J. Curran, Y. Kuraguchi, H. Hoshikawa, et al., A multiple shock tube and chemical kinetic modeling study of diethyl ether pyrolysis and oxidation, J. Phys. Chem. A., 114 (2010) 9098-9109 
[8] M. Werler, L.R. Cancino, R. Schiessl, U. Maas, C. Schulz, M. Fikri, Ignition delay times of diethyl ether measured in a high-pressure shock tube and a rapid compression machine, Proc. Combust. Inst., 35 (2015) 259-266

[9] 0. Herbinet, F. Battin-Leclerc, Progress in understanding low-temperature organic compound oxidation using a jet-stirred reactor, Int. J. Chem. Kinet., 46 (2014) 619-639

[10] R.J. Kee, F.M. Rupley, J.A. Miller, I.I. Chemkin, A fortran chemical kinetics package for the analysis of a gas-phase chemical kinetics SAND89-8009B, Sandia Laboratories (1993)

[11] A. Cuoci, A. Frassoldati, T. Faravelli, E. Ranzi, Comp. Phys. Com., 192 (2015) 237-264

[12] D. Healy, N.S. Donato, C.J. Aul, E.L. Petersen, C.M. Zinner, G. Bourque, H.J. Curran, n-Butane: Ignition delay measurements at high pressure and detailed chemical kinetic simulations, Combust. Flame., 157 (2010) 1526-1539

[13] L.-S. Tran, R. De Bruycker, H.-H. Carstensen, P.-A. Glaude, F. Monge, M.U. Alzueta, R.C. Martin, F. Battin-Leclerc, K.M. Van Geem, G.B. Marin, Combust. Flame, 162 (11) (2015) 4283-4303

[14] X. Zheng, J.W. Bozzelli, E.M. Fisher, F.C. Gouldin, L. Zhu, Experimental and computational study of oxidation of diethyl sulfide in a flow reactor, Proc. Combust. Inst., 33 (2011) 467-475

[15] C. Muller, V. Michel, G. Scacchi, G.M. Côme, THERGAS: a computer program for the evaluation of thermochemical data of molecules and free radicals in the gas phase, J. Chim. Phys., 92 (1995) 1154-1177

[16] Y.R. Luo, Handbook of Bond Dissociation Energies in Organic Compounds, CRC Press LLC (2003) 